\title{
DO ROMANCE ÀS CAPAS: FIGURAÇÃO E SOBREVIDA DA PERSONAGEM LOLITA
}

\section{FROM NOVEL TO COVERS: FIGURATION AND AFTERLIFE OF THE CHARACTER LOLITA}

\author{
Denize Helena Lazarin* \\ UFSM
}

Resumo: Este estudo teve por objetivo investigar a figuração da personagem Lolita, no romance de Nabokov, bem como em quatro de suas capas. As personagens vêm sendo objeto de estudo no âmbito literário por muito tempo; contudo, vem ocorrendo uma transcendência delas para outros meios, inclusive nas capas de livros, o que desperta interesse de estudos mais amplos. A capa, além de paratexto do livro, é usada amplamente pelo mercado editorial como elemento de marketing da obra. Em muitos casos, essas duas funções entram em atrito. A hipótese, neste texto, é de que os aspectos publicitários da obra acabam se tornando tão importantes que as editoras muitas vezes privilegiam alguns elementos do romance em detrimento de outros, tais como a femme fatale e a ninfeta, Como base para análise, foram utilizados os estudos de Reis (2014), Eder, Jannidis e Schneider (2010) e Sonzogni (2011).

Palavras-chave: Lolita. Nabokov. Personagem. Romance. Capas.

\begin{abstract}
This study aimed to investigate the figuration of the character Lolita, in Nabokov's novel, as well as in four of its covers. Characters have long been the object of study in the literary sphere; however, there has been a transcendence of them for other media, including on book covers, which has aroused interest in broader studies. The cover, in addition to the book's paratext, is widely used by the publishing market as marketing for the work. In many cases, these two functions collide. The hypothesis in this text is that the advertising aspects of the work end up becoming so important that publishers often favor some elements of the novel over others, such as the femme fatale and the nymphet. As a basis for the analysis, the studies conducted by Reis (2014), Eder, Jannidis and Schneider (2010) and Sonzogni (2011) were used.
\end{abstract}

Keywords: Lolita. Nabokov. Character. Novel. Covers.

\section{INTRODUÇÃO}

A arte em geral e a literatura em particular encontram na figura humana uma fonte privilegiada de inspiração. Muitas dessas figuras logo nos soam conhecidas; apesar de não as vermos diretamente nas ruas, nos são familiares. Algumas exercem influência sobre nós. Outras têm um elevado grau de complexidade e se parecem com pessoas reais, apesar das mediações

* Doutora em Estudos Literários pela Universidade Federal de Santa Maria (UFSM). ORCID: https://orcid.org/0000-0001-65679083. E-mail: <denizelazarin@yahoo.com.br>. 
miméticas próprias ao processo. Outras ainda são muito versáteis, modificam-se a partir da manifestação original que as gerou para sagrarem-se em outros meios.

Esse é o caso de Lolita, personagem homônima do famoso romance de Nabokov, publicado inicialmente pela editora francesa Olympia Press em 1955, devido à recusa dos editores americanos em trazer a público uma obra com o conteúdo tão polêmico. A partir de sua publicação, a personagem originou filmes, inspirou a criação de perfumes, publicidade em geral e estilo de moda. Ela ainda propiciou o surgimento de múltiplas faces a ela consagradas, nas capas de várias edições da narrativa mundo afora. Isso significa que estamos no campo de uma personagem tão consagrada pela literatura que sobrevive até fora dela. Neste artigo, pretendemos verificar como ocorre a figuração da personagem Lolita no romance de Nabokov e, também, em quatro capas de livros criadas a partir dele.

Desse modo, iniciamos este estudo tratando da figuração da personagem Lolita no romance de Nabokov, partindo sempre da premissa de que ela é representada a partir do olhar de Humbert, que, por sua vez, a constrói como lhe é mais conveniente. Como as capas de livro se constituem parte de nosso corpus, no tópico seguinte abordamos sua natureza dupla: ao mesmo tempo que se constituem paratexto, têm a função de marketing da obra. Ao discutirmos sobrevida da personagem além da literatura, analisamos como se dá a representação de Lolita nas capas da obra. Por fim, nas considerações finais, apresentamos a perspectiva na qual Lolita é representada neste corpus a partir de nossa leitura.

\section{FIGURAÇÃO DE PERSONAGEM E O ROMANCE DE NABOKOV}

O que é uma personagem? Etimologicamente, a palavra character vem do grego antigo charaktér, que significa uma ferramenta de estampar/marcar, compreendida em sentido figurado como uma marca de personalidade, algo que torna um ser único. O termo em língua portuguesa, personagem, vem do latim persona, que remete à máscara usada por um ator. De acordo com Heidbrink (2010), elas são partes de mundos ficcionais trazidas à vida por meios midiáticos, cujos seres humanos continuam sendo a referência dominante. No que tange à trama propriamente dita, Reis (2014 p. 49-50) defende que essa é uma categoria “[...] sem a qual não há relato que se sustente”.

Apesar de ser objeto de estudo por muitos séculos, foi apenas no século XIX que se desenvolveu uma análise mais descritiva e sistemática sobre personagens em várias disciplinas, tais como: estudos literários, história da arte, filosofia, psicologia, comunicação, estudos do cinema e das mídias. Para Eder, Jannidis e Schneider (2010), cada uma dessas disciplinas foi capaz de produzir uma infinidade de teorias que visam explicar a personagem, acabando muitas delas rivalizando. A partir delas, os críticos apresentam quatro paradigmas dominantes que possuem diferentes princípios, ênfases e métodos: abordagem hermenêutica, abordagem psicanalítica, teorias cognitivas e, finalmente, a abordagem estruturalista e semiótica.

Segundo os autores, a primeira toma as personagens predominantemente como seres humanos e enfatiza a necessidade de levar em consideração os backgrounds históricos e culturais delas e de sua criação. Por sua vez, a abordagem psicanalítica procura explicar a vida interior das personagens, como também “[...] as reações dos expectadores, usuários e leitores, com a ajuda de modelos de personalidade psico-dinâmicos” (EDER; JANNIDIS; SCHNEIDER, 2010, 
p. 5), como os desenvolvidos por Freud e Lacan. A teoria cognitiva “[...] centra-se na modelagem em detalhes das operações afetivas e cognitivas do processamento de informação”(EDER; JANNIDIS; SCHNEIDER, 2010, p. 5). Nesses estudos, personagens são consideradas como baseadas em constructos da mente humana e devem ser compreendidas como textos e como elementos da psique humana. Já a abordagem estruturalista e semiótica acredita na diferença entre personagens e seres humanos e procura explicá-las enquanto estruturas textuais. Os autores lembram que essas diferenças conceituais têm contribuído para uma fragmentação do campo de estudo.

As influências do formalismo russo e da análise estrutural da narrativa foram, por muito tempo, responsáveis por relegar a personagem a um papel subalterno. Para Reis:

O projeto estruturalista era, como se sabe, de índole translinguística; o seu aprofundamento semiótico, por exemplo na abordagem greimasiana, acentuou a dimensão funcionalista dos agentes narrativos, reduzidos à condição abstrata de papéis actanciais sem densidade humana. Exagerando um pouco, mas não muito, podemos dizer: nesse tempo o autor foi morto e levou consigo, para a cova que lhe abriram, a personagem, companhia solidária e a vários títulos conveniente [...]. (REIS, 2014, p. 50).

Mesmo os estudos de Genette, que ainda influenciam as leituras atuais, fixam-se na articulação do discurso e tratam a personagem como um efeito do texto. Felizmente, os estudos narratológicos abriram-se a influências interdisciplinares, tais como a psicanálise, a sociocrítica, a teoria da recepção e aos estudos fílmicos. E o que hoje conhecemos como estudos narrativos trouxeram ao nosso convívio novamente a personagem, que, segundo Reis (2014, p. 51), é uma “[...] figura que nenhuma narrativa dispensa, porque nela está inscrita uma temporalidade humana que é conatural à própria temporalidade da narrativa”. Essas novas influências não apenas trouxeram de volta a personagem em todo seu dinamismo, circulando por diversas áreas além do texto narrativo, mas também influenciaram o pensamento sobre o fazer personagem, ou seja, a figuração da personagem.

O termo “figura”, do latim figura, indica uma forma que contrasta com um fundo. Desse modo, etimologicamente, a figuração está ligada a uma imagem, mais especificamente à formação desta. A figuração envolve três dispositivos que estão interpenetrados na narrativa: de ficcionalização (ou paraficcionais), de conformação da ação ou comportamental, e discursivo (ou retórico-discursivo). Esse último, conforme abordado por Reis, diz respeito à necessidade de semiotização que requer uma personagem, ou seja, a figuração que a personagem reivindica, “[...] a articulação de um discurso que produz sentidos e que gera comunicação” (REIS, 2014, p. 56). Um exemplo desses operadores discursivos de figuração são pausas descritivas, "[...] para caracterização alargada em regime omnisciente” (REIS, 2014, p. 56), que cria literariamente retratos de personagens com potencial mimético. Dessa forma, para Reis (2014, p. 52, grifo do autor), “[...] o conceito de figuração designa um processo ou um conjunto de processos constitutivos de entidades ficcionais, de natureza e de feição antropomórfica, conduzindo à individualização de personagens em universos específicos, com os quais estas personagens interagem”.

O autor complementa que a figuração da personagem na narrativa é um processo dinâmico, gradual e complexo. Ela normalmente se elabora e se completa durante toda a narrativa, não 
relegada a um local específico do texto. Apesar da importância da descrição enquanto processo composicional da personagem, a figuração não depende só dela, devido a sua natureza dinâmica. Desse modo, para Reis (2014, p. 53, grifo do autor), “[... ] a figuração não é simplesmente um outro modo de entender a convencional caracterização, sendo antes um processo mais amplo, englobante e consequente”.

É exatamente isto que o ocorre em Lolita: durante todo o texto, o leitor obtém informações a respeito da personagem homônima, de modo a conceituá-la mentalmente. Em alguns momentos, obtemos informações diretas do narrador-protagonista, Humbert, a respeito da caracterização da garota, como, por exemplo, no início da obra:

Lolita, luz da minha vida, labareda em minha carne. Minha alma, minha lama. Loli-ta: a ponta da língua descendo em três saltos pelo céu da boca para tropeçar de leve, no terceiro, contra os dentes. Lo. Li. Ta.

Pela manhã era Lô, não mais que Lô, com seu metro e quarenta e sete de altura e calçando uma única meia soquete. Era Lola ao vestir os jeans desbotados. Era Dolly na escola. Era Dolores sobre a linha pontilhada. Mas em meus braços sempre foi Lolita. (NABOKOV, 2003, p. 11, grifo nosso).

Nesse excerto, conseguimos vislumbrar a complexidade do processo figurativo, conforme exposto por Reis. O único momento que Humbert caracteriza Lolita é quando fala de sua altura - um metro e quarenta e sete -, contudo, essa oração não está descontextualizada. Ela é uma em meio a outras várias em que ele descreve poeticamente, e com algumas frases de efeito, sua paixão pela garota. Se o leitor considerasse apenas a informação da altura da garota, ele ficaria chocado por se tratar de uma menina muito pequena, quase uma criança. Todavia, como a figuração é um processo englobante, ao mesmo tempo que o leitor se espanta com a informação, ele se comove com a amplitude e a dependência do amor que o protagonista sente por ela.

Esse processo ocorre em toda a narrativa, pois o narrador Humbert não deixa seu leitor, sobretudo o mais ingênuo, solto para formar com facilidade um juízo de valor contrário ao dele. De modo oposto, ele fornece informações, mas distorce as situações sempre enfatizando a dimensão e a dependência do seu amor pela garota. Essa dinâmica pode ser observada na segunda parte do romance, em que ele descreve seu comportamento depois da fuga de Lolita:

Era mais difícil separar-me de outras coisas dela. Até fins de 1949, venerei, manchando com meus beijos e minhas lágrimas de tritão, um par de estropiadas sandálias, uma camisa de menino que ela havia usado, alguns velhos jeans que descobri na mala do carro, um gorro escolar todo amassado e outros tesouros galhofeiros da mesma estirpe. (NABOKOV, 2003, p. 258).

É só depois de descrever seus infortúnios que ele apresenta um poema de própria autoria em que discorre sobre Lolita, apresentando caracterizações da garota:

Procura-se Dolores Haze, há grande urgência.

Tem cabelos castanhos e a pele é bronzeada.

Cinco mil e trezentos dias de existência.

Ocupação: artista de cinema - ou nada. 
(...) Um McKarma qualquer anda alegre, feliz, Conspurcando a mulher-criança em plena paz

E em cada estado desta terra onde se diz

Que é criminoso quem maltrata os animais

(...) Procura-se Dolores Haze em mil estradas.

Seus olhos são cruéis, sonhadores, tranquilos.

De altura apenas tem sessenta polegadas

E seu peso não passa de quarenta quilos

Meu carro, Dolly, já rateia, não resiste

À derradeira etapa, que é mais longa e dura.

O motor para, morre num gemido triste.

Das estrelas a poeira é tudo o que perdura.

(NABOKOV, 2003, p. 259-260).

A adolescente, agora com 14 anos e meio, tem cabelos castanhos e a pele bronzeada (ou lábios escarlates, como no original). Como ela cresceu desde o início da narrativa, agora está com um metro e cinquenta e dois de altura e não mais que quarenta quilos; contudo, continua sendo uma esposa-criança (child wife). Desse modo, apesar de permitir que o leitor vislumbre o quão jovem Lolita é, Humbert continua enfatizando a dimensão de seu sofrimento pela ausência dela.

Outro elemento largamente explorado por Humbert ao longo da narrativa é associar a garota com a ninfeta, o ser mítico criado por ele para designar as qualidades demoníacas de Lolita.

E nem ela é a frágil criança dos romances femininos. O que me leva a loucura é a natureza dupla desta ninfeta - talvez de todas as ninfetas; esta mistura em minha Lolita de uma infantilidade terna e sonhadora com uma espécie de estranha vulgaridade, derivada dos rostinhos atrevidos que aparecem nos anúncios e fotos de revista, das rosadas imagens de criadinhas adolescentes na Inglaterra (cheirando a feno), das jovens prostitutas disfarçadas de meninas nos bordeis do interior (NABOKOV, 2003, p. 46).

O termo ninfeta foi agregado ao léxico da língua inglesa graças à obra de Nabokov. A partir da entomologia, da qual Nabokov era hábil conhecedor, surge o termo que designa um ser que não completou todas as fases de seu amadurecimento; contudo, já tem a capacidade sexual. Segundo Humbert, Lolita não é apenas uma criança inocente. A mistura entre inocência e vulgaridade, próprias da natureza da ninfeta, é responsável pela dominação que a garota exerce sobre ele, levando-o a cometer seus atos ilícitos, cujo último foi o assassinato de Clare Quilty.

\section{A NATUREZA DUPLA DAS CAPAS: DO PARATEXTO AO MARKETING}

Desde a Idade Antiga até o Renascimento, a capa era um elemento de proteção e de ornamentação do livro. Com a invenção da imprensa, surgiu a necessidade de normatização. Assim, para que um texto se tornasse o livro físico, foi necessária a adoção de elementos verbais e não verbais, que ao mesmo tempo o envolvessem e fornecessem informações de forma mais 
contundente e clara a seu respeito. Segundo Genette (2009), sem a presença desses elementos pré-textuais e pós-textuais que orientam a leitura, a sequência de enunciados estaria nua.

Os elementos que cercam, prolongam e apresentam o texto são denominados paratextos. Eles apresentam não apenas no sentido de mostrar, mas na acepção expressiva do verbo de “[...] torná-lo presente, para garantir sua presença no mundo, sua 'recepção' e seu consumo” (GENETTE, 2009, p. 9, grifos do autor). Enquanto Borges compara-os a um vestíbulo, uma porta ou ambiente divisor de onde se pode escolher entre adentrar para um novo universo ou retroceder (BORGES apud GENETTE, 2009, p. 10), Lejeune vai mais além, defendendo que eles comandam toda a leitura (LEJEUNE apud GENETTE, 2009, p. 9).

Ao classificar os elementos que rodeiam o texto como pré-textuais e pós-textuais, Araújo (1986) cria uma nova classificação para a capa, lombada e orelha, denominando-os elementos extratextuais. Dentre esses elementos, a capa merece destaque devido à sua função publicitária, sendo apresentada em revestimento duro (encadernada) ou flexível (brochura). Straccia (2007), por sua vez, acredita que o

[...] gênero discursivo extratextual é, dentre todos, o que requer maiores cuidados já que lida com elementos que resultarão no primeiro impacto que o livro poderá causar no público. Em especial, na primeira capa, as decisões devem levar em conta tanto o caráter informacional - autor, título e editora - ou seja, a sua funcionalidade, quanto o apelo visual (escolher entre uma capa tipográfica ou desenhada; mais discreta ou mais agressiva; tipo grandes ou pequenos e assim por diante), neste caso, seu aspecto estético. (STRACCIA, 2007, p. 72).

No processo de produção do livro, estão envolvidos três profissionais principais: o autor, o editor e o designer ou capista. O editor, segundo Chartier (1999), além de ser o responsável por dar forma definitiva ao texto, é aquele que tem o papel de difundi-lo junto ao público leitor. É ainda o responsável pela escolha do designer que desenvolverá o projeto gráfico da obra. Entretanto, quais leis regem a produção desse paratexto? Que recursos essa produção deve conter? Do ponto de vista do design, Cavalcanti (1998) afirma que uma capa deve ter, entre outros elementos, muita cor para chamar atenção. Em depoimento, a autora defende que,

[...] quando um editor me chama para fazer uma capa, vai logo dizendo que eu estou livre para criar e vai passando as coordenadas: bota orelha - não bota orelha, mas acham orelha muito caro porque gasta papel... Formato? O de sempre. Não pode mudar. Os livreiros não suportam livros que não caibam nas prateleiras. Tem título (enorme, geralmente) e subtítulo para o leitor entender melhor o que o autor quis dizer com o título. Tem o nome do autor (ou vários). É importante? Vende muito? É artista de TV? Então coloca o nome bem grande. Grandão! Tem logotipo da editora na primeira capa, na quarta capa, na lombada. "Dá pra ser colorido? Dá pra ser maiorzinho?”. (CAVALCANTI, 1998, p. 3).

De acordo com Cavalcanti (1998), todos os elementos componentes do paratexto são variáveis e estão no âmbito da negociação entre capista e editor. Apesar de o autor não estar envolvido diretamente nessa relação de elaboração da capa, seu nome tem um peso, pois, de acordo com seu potencial de vendagem, ele pode ajudar na recepção da obra. Assim sendo, 
uma das questões que a designer levanta é a capacidade de vendagem, pois a capa é um entre diversos outros canais para a publicidade da obra.

Mauro Ferreira, outro capista, vai mais além: acredita que, guardadas as devidas proporções, a capa tem tanta importância quanto a obra (STRACCIA, 2007, p. 76). Para ele, o livro é um produto comercial e sua valorização começa pela capa, sendo considerada como um outdoor em seu processo de criação. Vitor Burton, por sua vez, também focaliza essa dimensão comercial do livro, pois a capa

[...] existe unicamente para ajudar a vender o livro. Na verdade, a capa é o único espaço publicitário garantido que as editoras têm. A editora tem aquele espaço de $14 \mathrm{~cm}$ por $21 \mathrm{~cm}$ e é com ele que deve disputar o espaço nas estantes das livrarias. Eu vejo a capa como um miniposter, um minioutdoor. Capa não é arte e capista não é artista. (STRACCIA, 2007, p. 76).

Nesse sentido, as capas operam uma tradução intersemiótica, ou seja, uma “[...] interpretação dos signos verbais por meio de sistemas de signos não-verbais” (JAKOBSON, 1969, p. 65) - nesse caso, signos visuais. A respeito desse processo, é necessário perceber que “[...] não funciona como substituto do texto fonte: a função primária, para o leitor, parece ser a exploração das possibilidades e das limitações do processo, que deve resultar num reconhecimento das diferenças midiáticas mais do que das semelhanças” (CLÜVER, 2011, p. 19).

Clüver (2006) salienta que, em um trabalho de tradução intersemiótica, o sentido atribuído ao texto original é resultado de uma interpretação. No caso de Lolita, percebemos uma diversidade de sentidos presente nas capas, cada qual ressaltando o aspecto do livro que mais lhe interessa. Muitas capas escamoteiam alguns aspectos do conteúdo, como a pedofilia, em detrimento de outros que são mais vendáveis, como o erotismo. Para Sonzogni (2011, p. 5), Lolita é frequentemente um "[...] exemplo onde os conteúdos do texto são suprimidos e negados nas mensagens visuais da capa”. A presença de capas que operam desse modo é observada na compilação organizada por Zimmer (2014), da qual selecionamos as quatro capas deste estudo. Em sua página da internet, ele apresenta 210 capas, de 40 países diferentes, em 59 anos da obra.

\section{PARA ALÉM DA LITERATURA: A PERSONAGEM SOBREVIVE}

Como vimos, personagens são entidades de mundos ficcionais trazidos à vida por meio de signos. Muitas são produzidas em uma linguagem específica e encontram dificuldades para serem transferidas. Outras, ao contrário, demonstram coerência em diferentes mídias. Muitas são provenientes da literatura; outras, por sua vez, são criadas por meio de outras mídias como teatro, filme, quadrinhos, televisão, rádio ou jogos de computador. Nesse segundo caso, elas trazem consigo características próprias da linguagem na qual foram criadas.

Desse modo, Eder, Jannidis e Schneider (2010) apresentam algumas características da personagem atreladas à linguagem midiática da qual são originárias. Para os autores, personagens apresentam características de movimento espaço-temporal condizentes com sua linguagem de criação: personagens de jogos de computador são dinâmicos, ao passo que as de pinturas e as de capas de livro são estáticas. As diferenças ainda estão relacionadas ao suporte tecnológico e à materialidade dos signos, pois personagens de teatro são transmitidas ao vivo, enquanto 
as de cinema não o são. Outro fator que promove diferença é o papel cultural e os métodos de produção e distribuição de diversas mídias. Dessa forma:

As mídias individuais preenchem uma série de funções dentro do sistema da mídia e seguem convenções bastante práticas: a produção de um filme é mais cara do que, digamos, a produção de um romance, e as considerações econômicas que isso acarreta frequentemente influenciam a criação de personagem. (EDER; JANNIDIS; SCHNEIDER, 2010, p. 18).

Uma característica cultural das personagens da capa, conforme observamos anteriormente, é que sua composição obedece às normas do mercado editorial, ou seja, tem o objetivo de persuadir leitores em potencial a comprarem a obra.

Personagens são também mecanismos de comunicação que servem a propósitos para além do universo ficcional. Normalmente as “[...] personagens contribuem para a função dos textos midiáticos dos quais fazem parte, como, por exemplo, promovendo o entretenimento, apreciação artística, educação, informação, distribuição de ideologias ou propaganda” (EDER; JANNIDIS; SCHNEIDER, 2010, p. 45). Em romances e filmes, elas servem aos propósitos da narrativa, ao passo que em videogames o propósito lúdico é o objetivo maior. Finalmente, nas capas, o objetivo é, além da função de paratexto, o anúncio da obra. Esse dinamismo com que a personagem circula em diversos meios torna necessária uma abordagem integrada para seu estudo.

As personagens ainda atuam diretamente na construção de sentidos, não sendo a ação, em muitas obras, o princípio organizador, mas, sim, o tema ou uma ideia. Uma variedade de sentidos associa-se às personagens, representada ou transmitida por elas, tais como ideias abstratas, virtudes, propriedades humanas, fenômenos como a morte, desejos ou medos, e mesmo referências a pessoas reais. Para Eder, Jannidis e Schneider (2010), a personificação, ou seja, a transformação de um princípio abstrato em personagem, é um exemplo desse processo. Um sentido amplamente personificado em muitas capas de Lolita é a femme fatale, ou seja, a propriedade da sedução atribuída à mulher, como podemos observar na capa de uma edição de 1998 da editora Gummerus (Figura 1): 
Figura 1: Lolita (Gummerus, 1998)

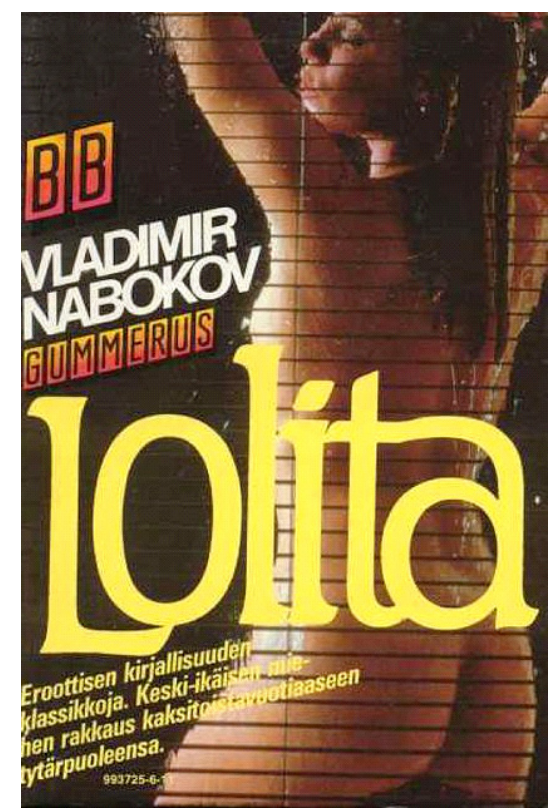

Fonte: Extraída de Zimmer (2014, n.p.).

Nessa capa, temos um corpo feminino nu de costas durante o banho, observado através de uma persiana aberta. A figura desnuda aparece sobre um fundo escuro a fim de destacar os elementos tipográficos dispostos sobre ele. O corpo feminino é alocado à direita enquanto o nome do autor em branco e o da editora em degradê são posicionados à esquerda da imagem. No centro da capa, em letras amarelas, está grafado o título, parte sobre o fundo escuro, parte sobre a cintura da mulher. Na parte inferior do lado esquerdo, está escrito, no idioma finlandês: “Clássicos da literatura erótica. Amor do homem de meia idade por sua enteada de doze anos”.

Por meio de cores quentes e contrastantes, bem como de imagens concretas, essa capa não sugere elementos dos conteúdos e da ambientação da obra, pois não é mencionado no texto de Nabokov nenhum momento que alguém observa Lolita tomar banho. No caso do gênero, essa capa vai ainda mais longe: induz o leitor em potencial ao erro ao reduzir a obra a um romance erótico. Essa capa opera como um convite ao leitor voyeur para espiar a nudez e vislumbrar a sensualidade da femme fatale, o que não ocorre na obra.

A figura da femme fatale às vezes é trabalhada pelas capas de modo mais explícito ainda, conforme mostra a Figura 2: 
Figura 2: Lolita (Gummerus, Jyvaskyla, 1992)

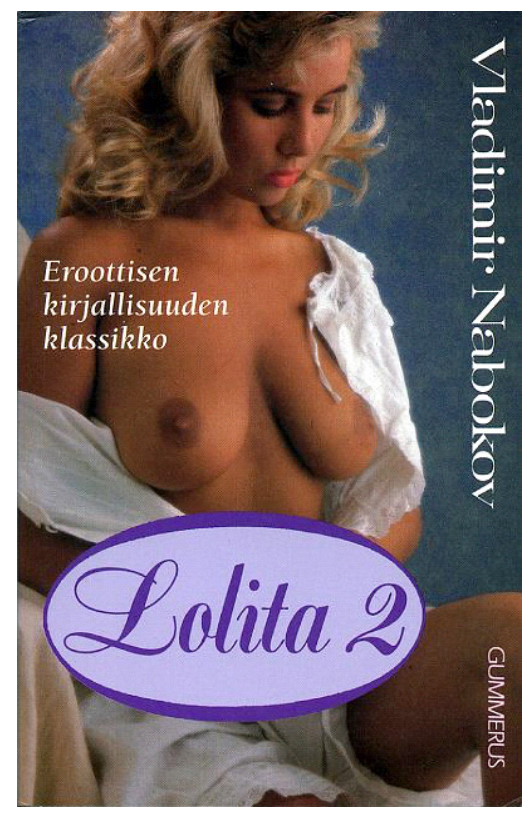

Fonte: Extraída de Zimmer (2014, n.p.).

Como podemos observar, a editora Gummerus demonstra predileção especial por femmes fatales em suas capas de Lolita. Se, na anterior (Figura 1), temos um nu de costas, na capa da Figura 2 visualiza-se a parte superior de um nu frontal. Como a anterior, por meio do uso de cores vibrantes e elementos concretos, essa capa também não expressa elementos do conteúdo, ambientação e gênero da obra. A imagem da jovem com os seios à mostra, com a informação explicativa fornecida pela editora “clássico da literatura erótica”, também induz ao erro, indicando tratar-se do subgênero literatura erótica e não drama, como é o caso.

Para Eder, Jannidis e Schneider (2010), a personagem é uma entidade que apresenta certa ambivalência tornando-se de difícil apreensão. Se, por um lado, ela está completamente integrada à obra da qual faz parte; por outro, ela parece se desprender com facilidade de seu contexto midiático. Assim, as personagens adquirem “[...] uma espécie de independência dos eventos em que vivem e que podem ser tratadas a alguma distância de seu contexto” (EDER; JANNIDIS; SCHNEIDER, 2010, p. 45), ou seja, ela é dotada de certa autonomia. Além disso, os textos literários, enquanto partes de narrativas ficcionais, possuem dimensão transhistórica, isto é, vão além do projeto literário do autor que as engendrou, transcendendo o texto do qual fazem parte. Para Reis,

[...] tendendo a universalizar os sentidos inerentes à sua condição de figuras ficcionais, certas personagens (Ulisses, Dom Quixote, Julien Sorel, Emma Bovary, Anna Karenina, Dom Casmurro, Blimunda, etc.) são sujeitas a refigurações de vária índole (dramatúrgica, cinematográfica, iconográfica, etc.) e ganham por isso uma sobrevida que merece uma atenção especial. (REIS, 2014, p. 54, grifo do autor). 
Essa refiguração, da qual a personagem literária é objeto, permite o que o autor chama de “efeitos de leitura desdobrados” (REIS, 2014, p. 46), ou seja, uma vez que ela é refigurada para outros meios, descobrem-se aspectos insuspeitados. Ocorre ainda um preenchimento de vazios, que é muito comum em atos transnarrativos e transliterários que envolvem o trabalho com imagem. Como exemplos desse processo, temos o cinema que emprestou as vozes de Sue Lyon e Dominique Swain a Lolita, nas adaptações fílmicas de Kubrick e Lyne, respectivamente (LAZARIN, 2010), e as capas que até hoje têm representado, das mais diversas formas por meio de ilustrações, um texto verbal.

Reis (2014) se questiona sobre o que permanece da personagem quando se encerra a leitura do texto literário. O que vemos em Lolita é que, ao mesmo tempo que a personagem ganha sobrevida por meio das refigurações, muitas delas modificam o sentido da personagem de Nabokov, agregando outros sentidos como a femme fatale, conforme vimos nas duas capas anteriores. Ele acredita que as personagens criadas por seus autores são “[...] projetadas para um destino transficcional e transliterário que o autor não domina” (REIS, 2014, p. 49), ou seja, elas vivem na mente dos autores, porém são independentes. Ele usa como exemplo a personagem Dom Quixote, de Cervantes; contudo, muitas de suas afirmações são aplicáveis a outras personagens, tais como a Lolita de Nabokov. Dessa maneira, não falamos em "cervantismo”, mas falamos de quixotismo, como também falamos em ninfeta, hoje à revelia de Nabokov. Esse é um sentido também muito explorado pelos designers.

Por meio de imagens concretas e de cores claras, que contrastam com o batom vermelho, a capa da edição de 1997 (Figura 3), da editora Gallimard, transmite elementos de gênero, conteúdo e ambiente:

Figura 3: Lolita (Gallimard, 1997)

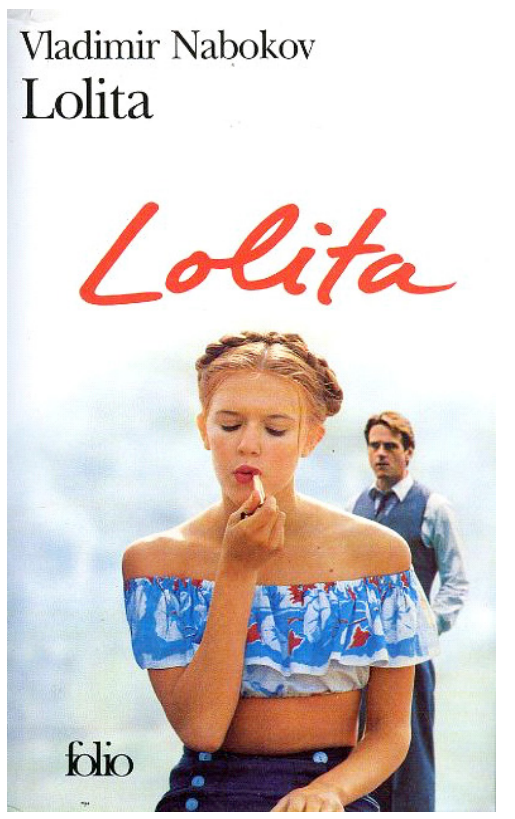

Fonte: Extraída de Zimmer (2014, n.p.). 
Baseada no cartaz de divulgação da adaptação cinematográfica de Lolita por Adrian Lyne, a capa tematiza a sedução ao exibir uma jovem garota (Dominique Swain), sem muita habilidade, passando em seus lábios um batom vermelho, um claro símbolo fálico. Desse modo, a menina de doze anos assume, aos olhos de Humbert, o papel da ninfeta que o seduz.

Em outros momentos, a imagem da ninfeta é abordada pelas capas de modo mais elaborado, conforme mostra a Figura 4:

Figura 4: Lolita (Mondadori, 1980)

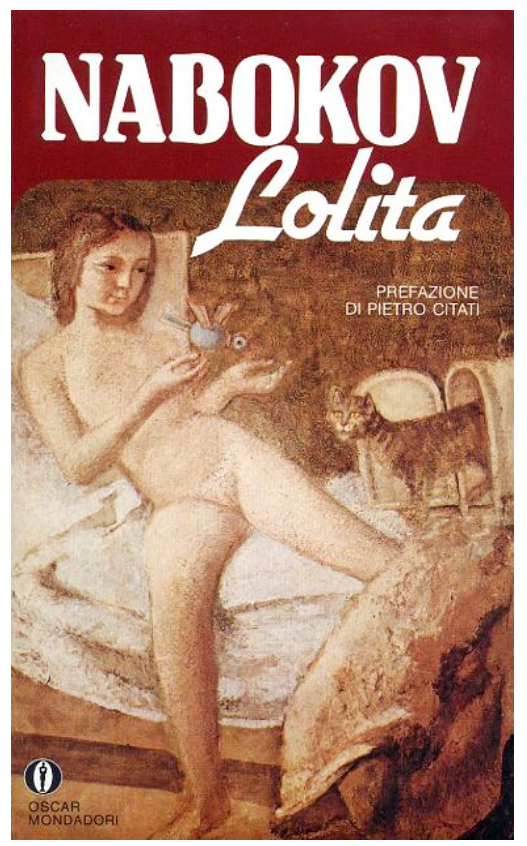

Fonte: Extraída de Zimmer (2014, n.p.).

Por meio de cores quentes e imagens concretas, a capa da editora Mondadori sugere elementos de gênero, de conteúdo e de ambientação. Enquanto temática, a imagem apresenta uma leitura da ninfeta: um ser entre adulto e criança. Ela brinca desatenta com um pássaro, o que é próprio do universo infantil, e, apesar de a figura estar nua, não denota sensualidade. O pássaro desatento, observado pelo gato, é uma leitura do drama de Lolita, tendo sempre Humbert à sua espreita, observando-a a fim de dar o bote. Essa imagem foi criada pelo artista Balthasar Klossowski, mais conhecido pelo pseudônimo de Balthus, mundialmente conhecido pela composição de criaturas inquietantes que habitavam um meio termo entre criança e mulher, nada mais próprio para a ninfeta de Humbert. Segundo Zimmer (2013, p. 74), “[...] elas sempre parecem exibir um elemento do surreal. De forma não convencional, elas poderiam ser interpretadas como meiga ou sexy, e elas se tornam eróticas apenas sob o olhar do espectador”.

Graças a essa transcendência, a ninfeta de Humbert ganhou vida passando a habitar as capas de muitas edições mundo afora. Nesse sentido, falando dessa sobrevida da obra literária, Reis, ao apropriar-se das palavras de Ingarden (1973), lembra que: 
1. A obra literária 'vive', na medida em que atinge a sua expressão numa multiplicidade de concretizações. 2. A obra literária 'vive, na medida em que sofre transformações em consequência de circunstâncias sempre novas estruturadas convenientemente por sujeitos conscientes. (INGARDEN apud REIS, 2014, p. 57).

O autor exemplifica essa afirmação na apropriação de uma personagem literária pela população da cidade espanhola de Oviedo: na praça da Catedral, existe uma estátua em tamanho natural de Ana Ozores, a protagonista do romance La Regenta (1884-1885), de Leopoldo Alas Clarin. Assim, a personagem fictícia está integrada ao espaço real, prevalecendo sobre a ficção que a gerou, o que, para Reis (2014), se constitui um processo ousado de metalepse. Ele pontua que não só elas sobrevivem para além das fronteiras da ficção, mas também o nome e suas qualidades e propriedades físicas, como, por exemplo, os olhos de ressaca de Capitu e o poder de sedução de ninfeta em Lolita.

No caso da sobrevida iconográfica, Reis (2014) alerta que esta pode causar a morte das indeterminações que estimulam a interpretação. Para o autor, “[...] ela é capaz ainda de potencializar criativos complementos daquilo que o romancista deixou por figurar na sua personagem” (REIS, 2014, p. 63), ou o que o autor não figurou propositalmente, como é o caso de Lolita. Flaubert se pronunciou contra qualquer possibilidade de dar rosto às suas personagens. Saramago, igualmente, relutou em aceitar as refigurações cinematográficas das suas. Nabokov, ao contrário, ainda em seu tempo, libertou Lolita no vasto mundo da cultura ao permitir a adaptação cinematográfica de Lolita por Stanley Kubrick, em 1962, sendo dela roteirista.

Ainda a esse respeito, Richardson (2010) acredita que devemos reconhecer

[...] a incapacidade de diferentes meios de comunicação para transmitir o mesmo grau de complexidade narrativa; podemos, portanto, concluir que a figura é a mesma na medida em que reproduz o caráter original, tanto quanto o outro meio convencionalmente permite. (RICHARDSON, 2010, p. 536).

Para o autor, na transposição para outra mídia, resulta uma personagem diferente, mais simples, em outras palavras, meramente uma versão. É inegável que essa versão compartilhe algumas qualidades com a original; todavia, a maioria delas tem poucos atributos essenciais, bem como um conjunto de características, que pode ou não ser incluída nas versões subsequentes.

Contudo, guardadas as devidas proporções, é importante ter em mente que, na transposição de um romance para a capa de um livro, é impossível que não ocorram reduções, pois uma capa não consegue englobar a complexidade e a extensão de um romance. Nas palavras de Bertram (2010, p. 1), é “[...] surpreendente como poucas dão conta da tarefa de comunicar algo que se aproxime da profundidade e complexidade do romance que transborda um poderoso imaginário primorosamente difundido”, como é o caso de Lolita.

\section{CONSIDERAÇÕES FINAIS}

Por muito tempo, os estudos literários estudaram a personagem enquanto estruturas textuais. Hoje, tenta-se compreender os mecanismos de sua figuração de forma mais globalizada, envolvendo até outras áreas do conhecimento humano. Por mais que haja uma relação entre 
personagens e seres humanos reais, visto que a composição das primeiras se vale muitas vezes dos segundos enquanto substrato, a análise literária foca nos aspectos composicionais da literatura que cria mundos possíveis, organizados coerentemente na diegese. Contudo, a personagem é capaz de sobressair-se ao universo literário e fazer sua morada em outras mídias, como as capas da obra, conforme abordamos aqui. Lolita despregou-se à revelia de Nabokov e seu romance. Assim como o quixotismo e o bovarismo, temos tanto a femme fatale quanto a ninfeta.

As capas na qualidade de paratextos são elementos de elevada importância, pois, ao mesmo tempo que protegem o texto, o apresentam, ou melhor, transformam o conteúdo verbal da obra em conteúdo visual. A partir do século XIX, uma segunda função da capa intensificou-se: a veiculação do marketing da obra. Todavia, às vezes, essas duas funções entram em conflito, pois nem sempre é possível ter compromisso com o conteúdo da obra e ao mesmo tempo se mostrar atraente ao leitor. Portanto, como tentamos evidenciar neste artigo, o que ocorre é que muitas editoras, como a Gummerus, preferem um caminho mais adequado a propósitos mercadológicos, visto que, em vez de retratarem uma criança abusada, optam por retratar Lolita enquanto uma femme fatale ou uma ninfeta, acatando, assim, o ponto de vista do narrador.

\section{REFERÊNCIAS}

ARAÚJO, M. A construção do livro. Rio de Janeiro: Editora Nova Fronteira, 1986.

BERTRAM, J. Lingerie, lollipops, lipsticks: inventing the perfect Lolita cover. Nabokov Online Journal, v. IV, 2010. Disponível em: http://venusfebriculosa.com/wpcontent/ uploads/2011/05/6_Bertram_Final.pdf. Acesso em: 23 out. 2019.

CAVALCANTI, M. Oitocentas capas. São Paulo: Logo Editora, 1998.

CHARTIER, R. A aventura do livro: do leitor ao navegador. São Paulo: Editora Unesp, 1999 CLÜVER, C. Intermidialidade. Pós - Revista do Programa de Pós-Graduação em Artes da Escola de Belas Artes da UFMG, Belo Horizonte, v. 1, n. 2, p. 8-23, nov. 2011. Disponível em: https://www.eba.ufmg.br/revistapos/index.php/pos/article/view/16/16. Acesso em: 7 maio 2019.

CLÜVER, C. Da transposição intersemiótica. In: ARBEX, M. (org.). Poéticas do visível: ensaios sobre a escrita e a imagem. Belo Horizonte: Ed. UFMG, 2006. p. 107-166.

EDER, J.; JANNIDIS, F.; SCHNEIDER, R. Introduction. In: EDER, J.; JANNIDIS, F.; SCHNEIDER, R. (org.). Characters in fictional worlds: Understanding imaginary beings in literature, fiction, and other media. Berlim: De Gruyter, 2010. p. 3-66.

GENETTE, G. Paratextos Editoriais. Cotia: Ateliê Editorial, 2009.

HEIDBRINK, H. Fictional characters in literary and media studies. In: EDER, J.; JANNIDIS, F.; SCHNEIDER, R. (org.). Characters in fictional worlds: Understanding imaginary beings in literature, fiction, and other media. Berlim: De Gruyter, 2010. p. 67-110.

JAKOBSON, R. Linguística e comunicação. São Paulo: Cultrix, 1969. 
LAZARIN, D. H. A representação cultural de Lolita do romance de Nabokov. 2010. Dissertação (Mestrado em Estudos Literários) - Universidade Federal de Santa Maria, Santa Maria, 2010.

NABOKOV, V. Lolita. São Paulo: Folha de S. Paulo, 2003.

REIS, C. Pessoas de livro: figuração e sobrevida da personagem. Revista de Estudos Literários, Coimbra, n. 4, p. 43-68, dez. 2014.

RICHARDSON, B. Transtextual characters. In: EDER, J.; JANNIDIS, F.; SCHNEIDER, R. (org.). Characters in fictional worlds: Understanding imaginary beings in literature, fiction, and other media. Berlim: De Gruyter, 2010. p. 527-541.

SONZOGNI, M. Re-covered rose: a case study in book cover design as intersemiotic translation. Philadelphia: John Benjamins Publishing Company, 2011.

STRACCIA, C. As marcas que se imprimem na capa de livros adaptados para o cinema e para a televisão. 2007. Tese (Doutorado em Comunicação Social) - Universidade Metodista de São Paulo, São Bernardo do Campo, 2007.

ZIMMER, D. E. Covering Lolita. (2014). Disponível em: http://www.dezimmer.net/ Covering\%20Lolita/LoCov.html. Acesso em: 16 jan. 2019.

ZIMMER, D. E. Dolly as a cover girl. In: BERTRAM, J.; LEVING, Y. (org.). Lolita: the story of a cover girl. Ohio: Print Books, 2013. p. 166-177. 